\title{
Comparison of Laminoplasty and Posterior Fusion Surgery for Cervical Ossification of Posterior Longitudinal Ligament
}

Hiroaki Nakashima ( $\sim$ hirospine@med.nagoya-u.ac.jp )

Nagoya University

Shiro Imagama

Nagoya University

Toshitaka Yoshii

Tokyo Medical and Dental University

\section{Satoru Egawa}

Tokyo Medical and Dental University

Kenichiro Sakai

Saiseikai Kawaguchi General Hospital

Kazuo Kusano

Kudanzaka Hospital

Yukihiro Nakagawa

Kihoku hospital

Takashi Hirai

Tokyo Medical and Dental University

Kanichiro Wada

Hirosaki University

Keiichi Katsumi

Niigata University Medicine and Dental General Hospital

Kengo Fujii

University of Tsukuba

Atsushi Kimura

Jichi Medical University

Takeo Furuya

Chiba University

Tsukasa Kanchiku

Yamaguchi University School of Medicine

Yukitaka Nagamoto

Osaka Rosai Hospital

Yasushi Oshima 
University of Tokyo

\section{Narihito Nagoshi}

Keio University

\section{Kei Ando}

Nagoya University

\section{Masahiko Takahata}

Hokkaido University

\section{Kanji Mori}

Shiga University

Hideaki Nakajima

University of Fukui

\section{Kazuma Murata}

Tokyo Medical University

\section{Shunji Matsunaga}

Imakiire General Hospital

\section{Takashi Kaito}

Osaka University

\section{Kei Yamada}

Kurume University

\section{Sho Kobayashi}

Hamamatsu University School of Medicine

\section{Satoshi Kato}

Kanazawa University

\section{Tetsuro Ohba}

University of Yamanashi

\section{Satoshi Inami}

Dokkyo Medical University

Shunsuke Fujibayashi

Kyoto University

\section{Hiroyuki Katoh}

Tokai University School of Medicine

\section{Haruo Kanno}

Tohoku University School of Medicine

\section{Yuanying Li}

Fujita Health University

\section{Hiroshi Yatsuya}

Nagoya University

\section{Masao Koda}

University of Tsukuba 


\section{Yoshiharu Kawaguchi}

University of Toyama

Katsushi Takeshita

Jichi Medical University

Morio Matsumoto

Keio University

Masashi Yamazaki

University of Tsukuba

Atsushi Okawa

Tokyo Medical and Dental University

\section{Research Article}

Keywords: laminoplasty, posterior fusion surgery, cervical, ossification of posterior longitudinal ligaments, cervical myelopathy, degenerative, instrumentation, C5 palsy, complication, outcome

Posted Date: May 13th, 2021

DOl: https://doi.org/10.21203/rs.3.rs-478135/v1

License: (c) (i) This work is licensed under a Creative Commons Attribution 4.0 International License. Read Full License

Version of Record: A version of this preprint was published at Scientific Reports on January 14th, 2022. See the published version at https://doi.org/10.1038/s41598-021-04727-1. 


\section{Abstract}

This prospective multicenter study formed by the Japanese Ministry of Health, Labour and Welfare at 27 institutions aimed to compare postoperative outcomes between laminoplasty (LM) and posterior fusion (PF) for cervical ossification of the posterior longitudinal ligament (OPLL). Controversy exists regarding the role of instrumented fusion in the context of posterior surgical decompression for OPLL. Among the 479 patients enrolled, 189 (137 and 52 patients with LM and PF, respectively) were included and evaluated using the Japanese Orthopaedic Association (JOA) scores, the JOA Cervical Myelopathy Evaluation Questionnaire (JOACMEQ), and radiographical measurements. Basic demographic and radiographical data were reviewed, and the propensity to choose a surgical procedure was calculated. Preoperatively, patient backgrounds, radiographical measurements (K-line or cervical alignment on X-ray, OPLL occupation ratio on computed tomography, and increased signal intensity change on magnetic resonance imaging), or clinical status (JOA score and JOACMEQ) after adjustments showed no significant differences. The overall risk of perioperative complications was lower in LM (odds ratio [OR] $0.40, p=0.006)$, and C5 palsy was significantly lower in LM $(O R 0.11, p=0.0002)$ than in PF. The range of motion $\left(20.91^{\circ} \pm 1.05^{\circ}\right.$ and $\left.9.38^{\circ} \pm 1.24^{\circ}, \mathrm{p}<0.0001\right)$ in patients with $\mathrm{PF}$ was significantly smaller than in those with LM. However, multivariable logistic regression analysis showed no significant difference in JOA score, JOA recovery rate, or JOACMEQ improvement at two years. In contrast, OPLL progression was greater in LM group than in the PF group (OR 2.73, $p=0.0002)$. LM and PF for cervical myelopathy due to OPLL resulted in comparable postoperative outcomes at two years after surgery.

\section{Introduction}

Ossification of the posterior longitudinal ligament (OPLL), defined as heterotopic bone formation in the posterior longitudinal ligament,[1] is a common cause of degenerative cervical myelopathy (DCM).[2] Surgical decompression is indicated in moderate and severe myelopathy (modified Japanese Orthopaedic Association (JOA) score $\leq 14$ )[3]; however, patients with OPLL are at a higher risk of perioperative complications than patients with other forms of DCM.[4] Surgical intervention includes anterior, posterior, or combined approaches, but the posterior approach is predominantly chosen for surgical treatment with multilevel decompression ( $\geq 3$ segments) because of its high complication rate in anterior or combined approaches.

Posterior surgeries include laminoplasty (LP) and laminectomy with fusion (PF); however, the optimal technique remains debatable. $[5,6] \mathrm{LP}$ is recognized as a standard technique for the treatment of cervical multi-segment DCM, and a preferable long-term outcome has been reported with its use in cervical OPLL compared to PF.[7-9] In contrast, however, some patients demonstrated poor results,[10] especially those who were K-line (-), and/or those with a high percentage of ossification occupation rate.[11-13] In addition, long-term follow-up has revealed increased ossification after LP, leading to reoperation.[14, 15] $\mathrm{PF}$ is another posterior procedure that has become widely used with the development of instruments. PF has a low risk of kyphotic change and ossification progression after surgery, and physicians believe that $\mathrm{PF}$ is preferable to LP in cases with severe ossification and/or in those that are K-line (-),[5] but sufficient 
scientific evidence has not been accumulated. Systematic review and meta-analysis comparing these procedures showed equivalent postoperative results; however, the details were unclear because there are limited numbers of small-scale prospective studies.[5] In particular, the size and types of OPLL have a considerable impact on the severity of myelopathy and the postoperative course, which makes comparisons difficult. In other words, the two techniques must be compared equally, taking into account the higher chance of including severe cases in PF.

Thus, the objective of the present study was to compare postoperative outcomes between LP and PF for cervical OPLL in a propensity score-matched analysis to adjust for baseline factors and radiographical characteristics of spinal cord compression.

\section{Methods}

This nationwide, multicenter, longitudinal study involved 28 academic institutions of the Japanese Multicenter Research Organization for Ossification of the Spinal Ligament formed by the Japanese Ministry of Health, Labour and Welfare. This study was approved by the Ethics committee of Tokyo Medical and Dental University (M2000-1963), and performed in accordance with the Declaration of Helsinki. All patients provided written, informed consent on entry into the registry. In total, 478 Japanese patients with cervical OPLL were prospectively enrolled from April 2015 to July 2017. Data were analyzed after obtaining approval from the Ethics Committee of all participating institutions. Patients were eligible for inclusion in the present study if they (1) were aged 20 years or older; (2) had imaging evidence of OPLL on computed tomography (CT) and spinal cord compression on magnetic resonance imaging (MRI); and (3) underwent surgery. All patients received surgical decompression for the cervical spine, and the attending surgeon dictated the surgical approach and the number of levels to decompress. A total of 369 cases were initially enrolled in this study, among which, 260 and 109 underwent LP and PF, respectively. We excluded 59 patients with preoperative comorbidities affecting neurological and lower limbs' function, including 25 patients with a thoracolumbar spine surgery, 15 with limb joint surgery, 5 with mental diseases with medications, 3 with Parkinson's disease, and 11 others; 34 patients with cervical spondylotic amyotrophy, spinal cord injury, or radiculopathy; and 39 patients with incomplete questionnaire data at two years after surgery were also excluded. In addition, 28 patients with incomplete radiographical followed-up data were excluded. Finally, the remaining 189 patients were included in the current study (Table 1). 
Table 1

Demographic parameters, preoperative radiographical parameters and quality of life in the original sample (before weighting) of patients undergoing laminoplasty or posterior spinal fusion.

\begin{tabular}{|c|c|c|c|c|}
\hline & & $\begin{array}{l}\text { Laminoplasty } \\
(\mathrm{n}=137)\end{array}$ & $\begin{array}{l}\text { Posterior spinal } \\
\text { fusion }(n=52)\end{array}$ & $\mathbf{p}$ \\
\hline Age (y) & & $64.2(11.6)$ & $63.9(10.6)$ & 0.85 \\
\hline Sex & (male ratio: \%) & 70.1 & 73.1 & 0.68 \\
\hline Body mass index & & $25.0(3.7)$ & $26.4(4.6)$ & 0.03 \\
\hline Smoking history (\%) & & 32.8 & 44.2 & 0.15 \\
\hline $\begin{array}{l}\text { Duration of } \\
\text { symptoms }\end{array}$ & & $46.5(74.7)$ & $40.9(55.7)$ & 0.63 \\
\hline Levels of surgery & & $3.4(0.9)$ & $4.9(1.5)$ & $<.0001$ \\
\hline \multirow[t]{6}{*}{ Comorbidities } & diabetes mellitus (\%) & 29.2 & 40.4 & 0.14 \\
\hline & hypertension (\%) & 40.9 & 30.8 & 0.20 \\
\hline & malignancy (\%) & 5.8 & 5.8 & 0.99 \\
\hline & $\begin{array}{l}\text { cerebrovascular disease } \\
(\%)\end{array}$ & 7.3 & 3.8 & 0.39 \\
\hline & myocardial infarction (\%) & 2.9 & 7.7 & 0.16 \\
\hline & collagen disease (\%) & 0.7 & 3.8 & 0.17 \\
\hline Drug & anticoagulant & 11.7 & 13.5 & 0.74 \\
\hline \multirow{6}{*}{$\begin{array}{l}\text { Radiographical } \\
\text { measurements }\end{array}$} & cervical lordosis $\left(^{\circ}\right)$ & $11.5(11.4)$ & $6.5(11.4)$ & 0.008 \\
\hline & range of motion $\left(^{\circ}\right)$ & $26.3(12.5)$ & $24.9(14.7)$ & 0.50 \\
\hline & K-line $(+/-)(\%)$ & 73 & 59.6 & 0.08 \\
\hline & $\begin{array}{l}\text { thickness of ossification } \\
(\mathrm{mm})\end{array}$ & $4.9(1.6)$ & $6.3(1.7)$ & $<0.0001$ \\
\hline & $\begin{array}{l}\text { spinal canal occupation } \\
\text { ratio }>60 \%(\%)\end{array}$ & 6.6 & 34.6 & $\dot{0} 0001$ \\
\hline & $\begin{array}{l}\text { increased signal intensity } \\
\text { on MRI (\%) }\end{array}$ & 85.4 & 90.4 & 0.37 \\
\hline JOA score & & $11.1(2.5)$ & $9.9(3.2)$ & 0.007 \\
\hline \multicolumn{5}{|c|}{$\begin{array}{l}\text { Summary statistics for continuous variables are means and standard deviations. JOA: Japanese } \\
\text { Orthopaedic Association; JOACMEQ: Japanese Orthopaedic Association Cervical Myelopathy } \\
\text { Evaluation Questionnaire; MRI: magnetic resonance imaging }\end{array}$} \\
\hline
\end{tabular}




\begin{tabular}{|lllll|}
\hline & & $\begin{array}{l}\text { Laminoplasty } \\
(\mathbf{n = 1 3 7 )}\end{array}$ & $\begin{array}{l}\text { Posterior spinal } \\
\text { fusion (n=52) }\end{array}$ & $\mathbf{p}$ \\
\hline JOACMEQ & cervical function & $63.0(27.7)$ & $53.8(31.0)$ & 0.0501 \\
\hline & upper limb function & $71.9(21.9)$ & $64.1(30.2)$ & 0.051 \\
\hline & lower limb function & $56.3(29.2)$ & $49.2(30.6)$ & 0.14 \\
\hline & bladder function & $73.3(20.0)$ & $72.0(26.7)$ & 0.71 \\
\hline Visual analog scale & $\begin{array}{l}\text { quality of life } \\
\text { pain or stiffness in the neck }\end{array}$ & $37.7(32.0)$ & $50.0(30.6)$ & 0.62 \\
\hline & $\begin{array}{l}\text { or shoulder } \\
\text { tightness in the chest }\end{array}$ & $9.7(20.9)$ & $13.0(20.3)$ & 0.03 \\
\hline & $\begin{array}{l}\text { pain or numbness in the } \\
\text { arms or hands }\end{array}$ & $58.4(31.1)$ & $68.8(25.8)$ & 0.046 \\
\hline & $\begin{array}{l}\text { pain or numbness from } \\
\text { chest to toe }\end{array}$ & $40.8(33.4)$ & $51.4(29.8)$ & 0.33 \\
\hline $\begin{array}{l}\text { Summary statistics for continuous variables are means and standard deviations. JOA: Japanese } \\
\text { Orthopaedic Association; JOACMEQ: Japanese Orthopaedic Association Cervical Myelopathy } \\
\text { Evaluation Questionnaire; MRl: magnetic resonance imaging }\end{array}$ & \\
\hline
\end{tabular}

\section{Data collection}

Data were collected for each participant, including demographic information, symptomatology, causative pathology, and surgical summary. Functional impairment, disability, and quality of life (QOL) were also evaluated preoperatively and at 24 months postoperatively. Basic demographic and clinical data, including age, sex, diabetes status, body mass index (BMI), smoking history, and disease duration, were collected for each patient.

\section{Evaluation}

\section{Clinical assessments}

Clinical status was evaluated using the cervical Japanese Orthopaedic Association (JOA) score and the Japanese Orthopaedic Association Cervical Myelopathy Evaluation Questionnaire (JOACMEQ) preoperatively and at two years post-surgery. The JOA recovery rate was calculated as follows: (postoperative JOA - preoperative JOA) / (17 - preoperative JOA)×100.[16] The minimum clinically important difference (MCID) of the JOA score and the JOA recovery rate were defined as 2.5 points and $52.8 \%$, respectively.[17] The JOACMEQ includes 24 questions covering the domains of cervical function, 
upper limb function, lower limb function, bladder function, and QOL.[18, 19] Scores for each domain were calculated according to official guidelines and range from 0 to 100 points, with a higher score indicating better health status. The JOACMEQ also incorporates visual analog scale (VAS) scores for pain or stiffness in the neck or shoulder, tightness in the chest, pain or numbness in the arms or hands, and pain or numbness from chest to toe. We evaluated improvement of JOACMEQ in each of its five domains. Clinically significant improvement was defined if 1 ) the patient answered all the questions necessary to calculate the functional score of a domain and an increase of $\geq 20$ points was obtained for that score, or 2) the functional score after treatment was $>90$ points, even if answers for any unanswered questions was considered to be the worst possible choice.

Each attending surgeon was also required to record all adverse events throughout the study period. A central panel of investigators classified each adverse event as related to surgery; any discrepancies among reviewers were resolved by consulting source documents. Perioperative complications were defined as surgery-related events occurring within 30 days of surgery.

\section{Radiographical assessments}

The most compressed level and the presence of a signal intensity change in the spinal cord were also investigated on mid-sagittal MRI.

The number of ossification levels (longitudinal extent of OPLL), K-line (positive or negative),[6] JOA welfare classification (continuous, segmental, mixed, and circumscribed),[4] spinal canal occupation ratio of OPLL on axial CT at the maximum cord compression level, and signal intensity change on T2 weight MRI were investigated.

The cervical lordotic angle ( $\mathrm{C} 2-7$ angle) and range of motion (ROM) in flexion-extension were also measured using tangential lines drawn on the posterior edge of the $\mathrm{C} 2$ and $\mathrm{C} 7$ vertebral bodies on lateral radiographs taken in a neutral position.

\section{Statistical analysis}

Propensity score methods were used to estimate treatment effects of observational data in the present study. A backward elimination logistic regression model was fitted to estimate the probability of treatment assignment, including all the relevant baseline variables with $p$-values less than 0.25 . In order to balance the distribution of baseline variables between treatment groups, a pseudo sample was created by weighting standardized inverse probability of treatment, in which we replaced extreme values of weight with those of the 1st and 99th percentiles. The Student t-test and Chi-square test were used to compare differences in means and proportions, respectively, of baseline covariates in the weighted sample. The covariates that were found to be different between the two groups with $p$-values less than 0.05 were further adjusted in the generalized linear model to compare treatment effects 30 days and 2 years after the operation. We calculated odds ratios (ORs) and the $95 \%$ confidence intervals $(95 \% \mathrm{Cls}$ ) for the dichotomized indices taking PF as the reference, and mean differences for the continuous variables adjusted for age, sex, and unbalanced variables. A two-sided p-value less than 0.05 was considered 
statistically significant. Statistical analysis was conducted using SAS version 9.4 (SAS Institute. Inc, Cary, NC, USA).

\section{Results}

Table 2 showed demographic parameters, preoperative radiographical parameters and QOL in the weighed sample (post propensity score matching) of patients undergoing LP or PF. There was no significant difference in age, sex, BMI, duration of symptoms, smoking history, or anticoagulant drug use. With respect to comorbidities, although there was no significant difference in diabetes mellitus, hypertension, malignancy, myocardial infarction, or collagen disease, the frequency of cerebrovascular disease was higher in the LP group than in the PF group $(7.4 \%$ and $1.4 \%$, respectively, $p=0.04)$. Baseline radiographical measurements were not significantly different between groups, as assessed by cervical lordosis, ROM, K-line, thickness of ossification, spina canal occupation ratio of the OPLL $>60 \%$, or increased signal intensity on MRI. Baseline functional status and QOL were also not significantly different, as assessed by JOA score or JOACMEQ. The two exceptions were the bladder function score in JOACMEQ, which was significantly higher in the PF group than in the LP group (mean (standard deviation, SD) of 79.7 (33.6) compared with 72.8 (20.5); $p=0.03$ ) and VAS pain or numbness in the arms or hands in JOACMEQ, which was significantly higher in the PF group than in the LP group (mean (SD) of 68.0 (32.8) compared with $59.9(32.4) ; p=0.048)$. 
Table 2

Demographic parameters, preoperative radiographical parameters, and quality of life in the weighed sample of patients undergoing laminoplasty or posterior spinal fusion.

\begin{tabular}{|c|c|c|c|c|}
\hline & & Laminoplasty & $\begin{array}{l}\text { Posterior } \\
\text { spinal fusion }\end{array}$ & $\mathbf{p}$ \\
\hline Age (yr) & & $64.3(11.9)$ & $66.7(14.7)$ & 0.13 \\
\hline Sex & (male ratio: \%) & 70.7 & 67.4 & 0.55 \\
\hline Body mass index & & $25.0(3.7)$ & $24.8(5.4)$ & 0.75 \\
\hline Smoking history (\%) & & 33.2 & 37.2 & 0.50 \\
\hline Duration of symptoms & & $44.4(75.1)$ & $41.9(81.7)$ & 0.80 \\
\hline Levels of surgery & & $3.5(0.9)$ & $3.6(2.3)$ & 0.96 \\
\hline \multirow[t]{6}{*}{ Comorbidities } & diabetes mellitus (\%) & 30.6 & 35.3 & 0.43 \\
\hline & hypertension (\%) & 41.6 & 36.9 & 0.45 \\
\hline & malignancy (\%) & 6.1 & 4.1 & 0.47 \\
\hline & cerebrovascular disease (\%) & 7.4 & 1.4 & 0.04 \\
\hline & myocardial infarction (\%) & 3.2 & 4.6 & 0.55 \\
\hline & collagen disease (\%) & 1.5 & 1.7 & 0.87 \\
\hline Drug & anticoagulant & 11.8 & 7.2 & 0.21 \\
\hline \multirow{6}{*}{$\begin{array}{l}\text { Radiographical } \\
\text { measurements }\end{array}$} & cervical lordosis $\left(^{\circ}\right)$ & $11.6(11.8)$ & $10.4(14.4)$ & 0.42 \\
\hline & range of motion $\left(^{\circ}\right)$ & $26.2(12.7)$ & $25.6(24.0)$ & 0.80 \\
\hline & K-line (+/-) (\%) & 73.6 & 65.2 & 0.14 \\
\hline & $\begin{array}{l}\text { thickness of ossification } \\
(\mathrm{mm})\end{array}$ & $5.1(1.7)$ & $5.3(2.8)$ & 0.34 \\
\hline & $\begin{array}{l}\text { spinal canal occupation ratio } \\
>60 \%(\%)\end{array}$ & 8.6 & 13.2 & 0.24 \\
\hline & $\begin{array}{l}\text { increased signal intensity on } \\
\text { MRI (\%) }\end{array}$ & 86.2 & 92.0 & 0.14 \\
\hline JOA score & & $10.9(2.6)$ & $10.6(4.4)$ & 0.55 \\
\hline \multirow[t]{2}{*}{ JOACMEQ } & cervical function & $61.8(28.0)$ & $57.0(44.1)$ & 0.24 \\
\hline & upper limb function & 70.5 (22.3) & $65.1(45.6)$ & 0.15 \\
\hline $\begin{array}{l}\text { Summary statistics for } \\
\text { Orthopedic Association } \\
\text { Evaluation Questionnai }\end{array}$ & $\begin{array}{l}\text { tinuous variables are means a } \\
\text { ACMEQ: Japanese Orthopaed } \\
\text { MRI: magnetic resonance imag }\end{array}$ & $\begin{array}{l}\text { standard devia } \\
\text { Association Cerv }\end{array}$ & $\begin{array}{l}\text { ons. JOA: Japa } \\
\text { cal Myelopathy }\end{array}$ & \\
\hline
\end{tabular}




\begin{tabular}{|c|c|c|c|c|}
\hline & & Laminoplasty & $\begin{array}{l}\text { Posterior } \\
\text { spinal fusion }\end{array}$ & $\mathrm{p}$ \\
\hline & lower limb function & $54.9(29.6)$ & $50.7(47.4)$ & 0.35 \\
\hline & bladder function & $72.8(20.5)$ & $79.7(33.6)$ & 0.03 \\
\hline & quality of life & $44.0(17.5)$ & $41.8(32.6)$ & 0.43 \\
\hline \multirow[t]{4}{*}{ Visual analog scale } & $\begin{array}{l}\text { pain or stiffness in the neck or } \\
\text { shoulder }\end{array}$ & $39.0(33.0)$ & $41.4(46.1)$ & 0.59 \\
\hline & tightness in the chest & $9.7(21.9)$ & $8.3(26.2)$ & 0.63 \\
\hline & $\begin{array}{l}\text { pain or numbness in the arms } \\
\text { or hands }\end{array}$ & $59.9(32.4)$ & $68.0(32.8)$ & 0.048 \\
\hline & $\begin{array}{l}\text { pain or numbness from chest } \\
\text { to toe }\end{array}$ & $42.2(34.4)$ & $47.5(52.9)$ & 0.29 \\
\hline \multicolumn{5}{|c|}{$\begin{array}{l}\text { Summary statistics for continuous variables are means and standard deviations. JOA: Japanese } \\
\text { Orthopedic Association; JOACMEQ: Japanese Orthopaedic Association Cervical Myelopathy } \\
\text { Evaluation Questionnaire; MRI: magnetic resonance imaging }\end{array}$} \\
\hline
\end{tabular}

Overall, perioperative complications were significantly lower in the LP group than in the PF group (17.0\% and $29.7 \%$, respectively, $p=0.02)$. In particular, C5 palsy was significantly more infrequent in the LP group than in the PF group ( $3.9 \%$ and $19.9 \%, p=0.0002)$; however, there was no significant difference in dural tear, wound disruption, wound infection, or revision surgery. Multivariable logistic regression analysis showed overall complications (OR $0.40,95 \% \mathrm{Cl} 0.21-0.77, \mathrm{p}=0.006)$ and $\mathrm{C} 5$ palsy $(\mathrm{OR} 0.11,95 \% \mathrm{Cl}$ $0.03-0.34, p=0.0002$ ) were significantly lower in the LP group than in the PF group (Table 3 ). 
Table 3

Logistic regression analysis for complications and revision surgery in the weighed sample of patients undergoing laminoplasty or posterior spinal fusion

\begin{tabular}{|c|c|c|c|}
\hline & OR & $95 \% \mathrm{Cl}$ & p \\
\hline Overall complications & 0.40 & $0.21-0.77$ & 0.006 \\
\hline C5 palsy & 0.11 & $0.03-0.34$ & 0.0002 \\
\hline Dural tear & 1.99 & $0.28-14.1$ & 0.49 \\
\hline Wound disruption & 0.26 & $0.02-3.62$ & 0.32 \\
\hline Deep wound infection & 0.54 & $0.11-2.60$ & 0.44 \\
\hline Superficial wound infection & 0.24 & $0.03-1.73$ & 0.16 \\
\hline Revision surgery & 0.31 & $0.01-11.10$ & 0.52 \\
\hline \multicolumn{4}{|c|}{$\begin{array}{l}\text { Weighted for IPTW and further adjusted for baseline age, sex, VAS } \square \text { pain or numbness in the arms or } \\
\text { hands } \rrbracket \text {, preoperative JOACMEQ } \square \text { bladder function } \rrbracket \text {, preoperative comorbidity } \llbracket \text { cerebrovascular disease }\end{array}$} \\
\hline \multicolumn{4}{|c|}{$\begin{array}{l}\text { IPTW: inverse probability of treated weighting; JOACMEQ: the Japanese Orthopaedic Association } \\
\text { Cervical Myelopathy Evaluation Questionnaire; OR: odds ratio; CI: confidence intervals; VAS visual } \\
\text { analogue scale }\end{array}$} \\
\hline
\end{tabular}

Patients achieved similar postoperative functional and QOL outcomes on JOA score, JOA recovery rate, and JOACMEQ score (Table 4). There were also no significant radiographical differences between groups (Table 4). ROM and JOACMEQ cervical function score were significantly smaller in the PF group compared to the LP group $(20.91 \pm 1.05$ and $9.38 \pm 1.24, p<0.0001 ; 67.64 \pm 2.78$ and $55.46 \pm 3.29, p=$ 0.005 , respectively) (Table 4). Multivariable logistic regression analysis showed no significant difference in JOA score $>$ MCID, JOA recovery rate $>M C I D$, or clinically significant improvement in JOACMEQ (Table 5). The percentage of patients with progression in the thickness of OPLL was significantly higher in the LP group than in the PF group (56.0\% vs. $30.5 \%$ in PF; OR $2.73,95 \% \mathrm{Cl} 1.60-4.67, \mathrm{p}=0.0002)$ (Table 5). 
Table 4

Two years postoperative radiographical parameters and quality of life in the weighed sample of patients undergoing laminoplasty or posterior spinal fusion.

\begin{tabular}{|c|c|c|c|c|}
\hline & & Laminoplasty & $\begin{array}{l}\text { Posterior } \\
\text { spinal fusion }\end{array}$ & p \\
\hline \multirow{3}{*}{$\begin{array}{l}\text { Radiographical } \\
\text { measurements }\end{array}$} & cervical lordosis $\left(^{\circ}\right)$ & $9.69(1.10)$ & $7.66(1.30)$ & 0.24 \\
\hline & range of motion $\left(^{\circ}\right)$ & $20.91(1.05)$ & $9.38(1.24)$ & $\hat{0}_{0.0001}$ \\
\hline & $\begin{array}{l}\text { thickness of ossification } \\
(\mathrm{mm})\end{array}$ & $6.11(0.54)$ & $4.80(0.64)$ & 0.12 \\
\hline \multicolumn{2}{|l|}{ JOA score } & $13.73(0.21)$ & $13.72(0.25)$ & 0.97 \\
\hline \multicolumn{2}{|l|}{ JOA RR } & $45.84(3.08)$ & $51.15(3.65)$ & 0.27 \\
\hline \multirow{5}{*}{ JOACMEQ } & cervical function & $67.64(2.78)$ & $55.46(3.29)$ & 0.005 \\
\hline & upper limb function & $80.45(1.76)$ & $77.53(2.08)$ & 0.29 \\
\hline & lower limb function & $63.44(2.44)$ & 56.19 (2.89) & 0.058 \\
\hline & bladder function & 77.19 (1.62) & $76.12(1.92)$ & 0.67 \\
\hline & quality of life & $53.63(1.64)$ & $50.77(1.94)$ & 0.27 \\
\hline \multirow[t]{4}{*}{ Visual analog scale } & $\begin{array}{l}\text { pain or stiffness in the neck } \\
\text { or shoulder }\end{array}$ & $35.85(2.78)$ & 38.18 (3.29) & 0.59 \\
\hline & tightness in the chest & $9.94(1.80)$ & $7.80(2.13)$ & 0.89 \\
\hline & $\begin{array}{l}\text { pain or numbness in the } \\
\text { arms or hands }\end{array}$ & $39.84(2.70)$ & $44.20(3.20)$ & 0.30 \\
\hline & $\begin{array}{l}\text { pain or numbness from chest } \\
\text { to toe }\end{array}$ & $33.10(2.83)$ & 34.78 (3.35) & 0.70 \\
\hline \multicolumn{5}{|c|}{$\begin{array}{l}\text { Values are means and standard errors. Weighted for IPTW and further adjusted for baseline age, sex, } \\
\text { VAS } \square \text { pain or numbness in the arms or hands } \rrbracket \text {, preoperative CMEQ } \square \text { bladder function } \rrbracket \text {, preoperative } \\
\text { comorbidity } \llbracket \text { cerebrovascular disease } \square\end{array}$} \\
\hline \multicolumn{5}{|c|}{$\begin{array}{l}\text { JOA: Japanese Orthopaedic Association; JOACMEQ: Japanese Orthopaedic Association Cervical } \\
\text { Myelopathy Evaluation Questionnaire; IPTW: inverse probability of treated weighting; VAS visual } \\
\text { analogue scale }\end{array}$} \\
\hline
\end{tabular}


Table 5

Logistic regression analysis for postoperative functional outcome and progression of OPLL in in the weighed sample of patients undergoing laminoplasty or posterior spinal fusion

\begin{tabular}{|c|c|c|c|c|}
\hline & & OR & $95 \% \mathrm{Cl}$ & $\mathbf{p}$ \\
\hline JOA score > MCID & & 0.98 & $0.57-1.68$ & 0.94 \\
\hline JOA RR > MCID & & 0.88 & $0.50-1.53$ & 0.64 \\
\hline \multirow[t]{5}{*}{ Clinical improvement of JOACMEQ } & cervical function & 1.05 & $0.58-1.87$ & 0.88 \\
\hline & upper limb function & 1.04 & $0.57-1.89$ & 0.90 \\
\hline & lower limb function & 1.75 & $0.89-3.44$ & 0.11 \\
\hline & bladder function & 1.16 & $0.59-2.28$ & 0.67 \\
\hline & quality of life & 1.88 & $0.95-3.70$ & 0.07 \\
\hline Progression of OPLL & & 2.73 & $1.60-4.67$ & 0.0002 \\
\hline \multicolumn{5}{|c|}{ 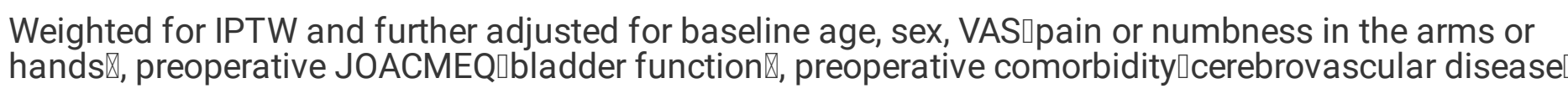 } \\
\hline \multicolumn{5}{|c|}{$\begin{array}{l}\text { JOA: Japanese Orthopaedic Association; JOACMEQ: Japanese Orthopaedic Association Cervical } \\
\text { Myelopathy Evaluation Questionnaire; OR: odds ratio; Cl: confidence intervals; OPLL: Ossification of } \\
\text { the posterior longitudinal ligament; MCID: minimum clinically important difference; IPTW: inverse } \\
\text { probability of treated weighting; VAS visual analogue scale }\end{array}$} \\
\hline
\end{tabular}

\section{Discussion}

This nationwide, multicenter, prospective study provides a comprehensive evaluation of the relative efficacy of LP and PF for patients with cervical OPLL. Comparable improvement was observed among patients with OPLL in both surgical procedures two years post-operation. The exceptions to this were the JOACMEQ cervical function scores and the cervical ROM on X-ray (Table 4), which were lower and smaller in the patients with PF than in those with LP. In contrast, logistic regression analysis revealed no clinically significant difference in the improvement of JOACMEQ cervical function (Table 5), and thus this difference might have a limited effect on the outcome of cervical function.

A relatively high incidence of surgical complications for cervical OPLL compared with other forms of DCM has been reported; neurologic deficit and neck pain are common in posterior procedures. $[4,20] \mathrm{In}$ the current study, the overall complication rate (OR 0.40) and C5 palsy (OR 0.11) was significantly lower in LP compared with PF. Although the pathology of postoperative C5 palsy is still debated, iatrogenic foraminal stenosis and larger posterior shift of the spinal cord might be associated with a higher risk of C5 palsy in PF.[21, 22] Takemitsu et al. reported that the higher risk of postoperative C5 palsy with posterior instrumentation was 11.6 times greater than that without instrumentation,[23] and this relative risk was similar to the current result. However, the actual incidence of C5 palsy after posterior procedures 
remains unclear with some retrospective studies having reported it as $0-30 \%$ and $2.6-50 \%$ in LP and PF, respectively.[21-25] This prospective study, however, demonstrated that the risk of C5 palsy was 10 times higher in posterior instrumentation; thus, prophylactic foraminotomy might be recommended to reduce C5 palsy in cases with PF.[24, 25]

Neck pain was reported as another common postoperative complication in cervical OPLL, compared with other forms of DCM,[4] and postoperative cervical kyphotic alignment might be associated with neck pain. Few studies have compared these complications between different posterior procedures in cervical OPLL. However, pain or stiffness in the neck or shoulder was comparable in the two procedures (Table 4). Prior to the current study, we hypothesized that postoperative kyphotic alignment change was more frequent in LP than in PF, which might be associated with postoperative neck pain. There were, however, no differences in radiographical alignment and degree of postoperative neck pain between groups. Machino et al. reported that the kyphotic alignment change after laminoplasty was observed in $7.2 \%$ of 457 cases with preoperative lordotic alignment, and the incidence of postoperative kyphotic change was relatively low.[26] Although kyphotic change after LP was reported in another report,[27] cervical alignment is maintained in the majority of cases if patient selection is appropriate.

With respect to functional and QOL outcomes at two years, there were significant differences in the average scores on the JOACMEQ cervical function domain and cervical ROM on X-ray (Table 4). The cervical function of the JOACMEQ is based on the results of four questions about activities of daily living that require neck up-and-down and rotation.[19] PF reduced ROM, which might be associated with its lower cervical function score in the JOACMEQ. Although JOACMEQ has criteria for determining whether these differences are clinically meaningful improvements, multivariate analysis showed no significant differences in postoperative improvement of cervical function. Therefore, the effect on the QOL was considered to be limited, though there was a numerical difference. Furthermore, although the perioperative complication of C5 palsy was frequent in PF, the majority of C5 palsy cases improved at two years. Therefore, this complication was not associated with significant negative outcomes at two years post-surgery.

Although reoperation for the progression of OPLL after LP was not observed in the two postoperative years reviewed in the current study, revision surgery around 10 years after LP has been reported.[14, 15] OPLL progression is commonly observed after LP[7, 8]; 70\% of patients showed an increase in OPLL size 10 years after surgery.[15] The size of ossification commonly increases in young adults, those with continuous- or mixed-type OPLL, and those with kyphotic alignment change.[14, 15] Thus, there is a possibility of long-term deterioration in the QOL, and careful follow-up is mandatory.

\section{Strengths and limitations}

The findings of this study are likely to be more generalizable than findings from single-center studies since patients were prospectively enrolled at 24 multicenter sites. The large number of recruitment sites allowed us to evaluate outcomes for 189 patients with OPLL and LP or PF. In addition, we evaluated 
outcomes using different radiographical and questionnaire tools, allowing for a comprehensive assessment of surgical outcomes in patients with OPLL.

This study has several limitations. First, a 26\% attrition rate was observed at the two-year time point. Second, this is not an international study, and clinical outcomes depending on racial differences could exist. Third, a standardized surgical protocol was not utilized across centers and decisions about the approach, number of decompressed levels, and use of instrumentation and fusion were made at the discretion of the attending surgeon. Some baseline covariates were unbalanced between the two treatment groups in the weighted sample, and there may be residual systematic differences for other measured and unmeasured baseline covariates, which may yield a biased estimate of treatment effects. Although a backward elimination logistic regression model was used for baseline adjustment, PF was performed in more severe cases with less cervical lordosis or with larger spinal canal occupation of OPLL compared with LP. Therefore, a future prospective large-scale multicenter international study is needed to validate the current results.

In conclusion, cervical LP and PF provides almost comparable functional and QOL improvements at two years after surgery, although perioperative complications were higher in PF.

\section{Declarations}

\section{Acknowledgements}

This work was supported by Health and Labour Science Research grants (H29-nanchi(nan)-ippan-040) and by a grant from the Japan Agency for Medical Research and Development (16ek0109136h0002). There are no other financial associations that may be relevant or seen as relevant to this work.

\section{Author contributions}

H.N., S.I., T.Y., M.K., Y.L., and H.Y. designed the study; H.N., S.I., T.Y., S.E., K.S., K.K., Y.N., T.H., K.W., K.K., K.F., A.K., T.F., T.K., Y.N., Y.O., N.N., K.A., M.T., K.M., H.N., K.M., S.M., T.K., K.Y., S.K., S.K., T.O., S.I., S.F., H.K., H.K., and M.K. collected the data; H.N., S.I., T.Y., M.K., Y.L., and H.Y. analyzed and interpreted the data; H.N., S.I., T.Y., M.K., Y.L., and H.Y. wrote the initial draft of the manuscript; H.N., Y.L., and H.Y. performed the statistical analyses. M.Y., A.O., and Y.K. supervised the study. M.M., M.Y., and A.O. acquired the funding. All authors read and approved the final manuscript.

\section{Competing interests}

The authors declare no competing interests.

\section{References}


1. Hashizume, Y. Pathological studies on the ossification of the posterior longitudinal ligament (opll). Acta Pathol. Jpn. 30, 255-273 (1980). 10.1111/j.1440-1827.1980.tb01320.x, Pubmed:6770578

2. Nouri, A., Tetreault, L., Singh, A., Karadimas, S. K. \& Fehlings, M. G. Degenerative Cervical Myelopathy: Epidemiology, Genetics, and Pathogenesis. Spine (Phila Pa 1976) 40, E675-E693 (2015). 10.1097/BRS.0000000000000913, Pubmed:25839387

3. Fehlings, M. G., et al. Change in functional impairment, disability, and quality of life following operative treatment for degenerative cervical myelopathy: A systematic review and meta-analysis. Global Spine J. 7 Suppl, 53S-69S (2017). 10.1177/2192568217710137, Pubmed:29164033

4. Nakashima, H., et al. Comparison of outcomes of surgical treatment for ossification of the posterior longitudinal ligament versus other forms of degenerative cervical myelopathy: Results from the Prospective, Multicenter AOSpine CSM-International Study of 479 Patients. J. Bone Joint Surg. Am. 98, 370-378 (2016). 10.2106/JBJS.0.00397, Pubmed:26935459

5. Ma, L., et al. Comparison of laminoplasty versus laminectomy and fusion in the treatment of multilevel cervical ossification of the posterior longitudinal ligament: A systematic review and metaanalysis. Med. (Baltim.) 97, e11542 (2018). 10.1097/MD.0000000000011542, Pubmed:30024545

6. Yuan, X., et al. Comparison of laminectomy and fusion vs laminoplasty in the treatment of multilevel cervical spondylotic myelopathy: A meta-analysis. Med. (Baltim.) 98, e14971 (2019).

10.1097/MD.0000000000014971, Pubmed:30921202

7. Kawaguchi, Y., et al. Minimum 10-year followup after en bloc cervical laminoplasty. Clin. Orthop. Relat. Res. 411, 129-139 (2003). 10.1097/01.blo.0000069889.31220.62, Pubmed:12782868

8. Chiba, K., et al. Long-term results of expansive open-door laminoplasty for cervical myelopathy Average 14-year follow-up study. Spine 31, 2998-3005 (2006).

10.1097/01.brs.0000250307.78987.6b, Pubmed:17172996

9. Ogawa, Y., et al. Long-term results of expansive open-door laminoplasty for ossification of the posterior longitudinal ligament of the cervical spine. J. Neurosurg. Spine 1, 168-174 (2004). 10.3171/spi.2004.1.2.0168, Pubmed:15347002

10. Nakashima, H., et al. Prediction of outcome following surgical treatment of cervical myelopathy based on features of ossification of the posterior longitudinal ligament: A systematic review. JBJS Rev. 5, 01874474-201702000-00003 (2017). 10.2106/JBJS.RVW.16.00023, Pubmed:28248739

11. Fujiyoshi, T., et al. A new concept for making decisions regarding the surgical approach for cervical ossification of the posterior longitudinal ligament: the K-line. Spine 33, E990-E993 (2008). 10.1097/BRS.0b013e318188b300, Pubmed:19092610

12. Iwasaki, M., Kawaguchi, Y., Kimura, T. \& Yonenobu, K. Long-term results of expansive laminoplasty for ossification of the posterior longitudinal ligament of the cervical spine: more than 10 years follow up. J. Neurosurg. 96 Suppl, 180-189 (2002). 10.3171/spi.2002.96.2.0180, Pubmed:12450281

13. Iwasaki, M., et al. Surgical strategy for cervical myelopathy due to ossification of the posterior longitudinal ligament: part 1: Clinical results and limitations of laminoplasty. Spine (Phila Pa 1976) 32, 647-653 (2007). 10.1097/01.brs.0000257560.91147.86, Pubmed:17413469 
14. Nakashima, H., et al. Reoperation for late neurological deterioration after laminoplasty in individuals with degenerative cervical myelopathy: comparison of cases of cervical spondylosis and ossification of the posterior longitudinal ligament. Spine 45, E909-E916 (2020).

10.1097/BRS.0000000000003408, Pubmed:32675602

15. Chiba, K., et al. Multicenter study investigating the postoperative progression of ossification of the posterior longitudinal ligament in the cervical spine: a new computer-assisted measurement. J. Neurosurg. Spine 3, 17-23 (2005). 10.3171/spi.2005.3.1.0017, Pubmed:16122017

16. Hirabayashi, K., Miyakawa, J., Satomi, K., Maruyama, T. \& Wakano, K. Operative results and postoperative progression of ossification among patients with ossification of cervical posterior longitudinal ligament. Spine (Phila Pa 1976) 6, 354-364 (1981). 10.1097/00007632-19810700000005, Pubmed:6792717

17. Kato, S., et al. Does posterior scoliosis correction improve respiratory function in adolescent idiopathic scoliosis? A systematic review and meta-analysis. Global Spine J. 9, 866-873 (2019). 10.1177/2192568218811312, Pubmed:31819853

18. Fukui, M., et al. Japanese Orthopaedic Association Cervical Myelopathy Evaluation Questionnaire (JOACMEQ): part 4. Establishment of equations for severity scores. Subcommittee on low back pain and cervical myelopathy, evaluation of the clinical outcome committee of the Japanese Orthopaedic Association. J. Orthop. Sci. 13, 25-31 (2008). 10.1007/s00776-007-1194-2, Pubmed:18274852

19. Ando, K., et al. Outcomes of surgery for thoracic myelopathy owing to thoracic ossification of the ligamentum flavum in a nationwide multicenter prospectively collected study in 223 patients: is instrumented fusion necessary? Spine (Phila Pa 1976) 45, E170-E178 (2020).

10.1097/BRS.0000000000003208, Pubmed:31415461

20. Li, H. \& Dai, L. Y. A systematic review of complications in cervical spine surgery for ossification of the posterior longitudinal ligament. Spine J. 11, 1049-1057 (2011). 10.1016/j.spinee.2011.09.008, Pubmed:22015235

21. Nakashima, H., et al. Multivariate analysis of C-5 palsy incidence after cervical posterior fusion with instrumentation. J. Neurosurg. Spine 17, 103-110 (2012). 10.3171/2012.4.SPINE11255, Pubmed:22632173

22. Hojo, Y., et al. A late neurological complication following posterior correction surgery of severe cervical kyphosis. Eur. Spine J. 20, 890-898 (2011). 10.1007/s00586-010-1590-8, Pubmed:20936306

23. Takemitsu, M., Cheung, K. M. C., Wong, Y. W., Cheung, W. Y. \& Luk, K. D. C5 nerve root palsy after cervical laminoplasty and posterior fusion with instrumentation. J. Spinal Disord. Tech. 21, 267-272 (2008). 10.1097/BSD.0b013e31812f6f54, Pubmed:18525487

24. Nakashima, H., et al. Complications of cervical pedicle screw fixation for nontraumatic lesions: a multicenter study of 84 patients. J. Neurosurg. Spine 16, 238-247 (2012).

10.3171/2011.11.SPINE11102, Pubmed:22176430 
25. Katsumi, K., Yamazaki, A., Watanabe, K., Ohashi, M. \& Shoji, H. Can prophylactic bilateral C4/C5 foraminotomy prevent postoperative C5 palsy after open-door laminoplasty?: a prospective study. Spine 37, 748-754 (2012). 10.1097/BRS.0b013e3182326957, Pubmed:21912316

26. Machino, M., et al. Cervical alignment and range of motion after laminoplasty: radiographical data from more than 500 cases with cervical spondylotic myelopathy and a review of the literature. Spine (Phila Pa 1976) 37, E1243-E1250 (2012). 10.1097/BRS.0b013e3182659d3e, Pubmed:22739671

27. Kim, T. H., Lee, S. Y., Kim, Y. C., Park, M. S. \& Kim, S. W. T1 slope as a predictor of kyphotic alignment change after laminoplasty in patients with cervical myelopathy. Spine 38, E992-E997 (2013). 10.1097/BRS.0b013e3182972e1b, Pubmed:23609205 